\title{
Empirical ground support design of mine drives
}

\author{
Y Potvin Australian Centre for Geomechanics, The University of Western Australia, Australia
}

J Hadjigeorgiou University of Toronto, Canada

\begin{abstract}
The majority of Australian and Canadian underground hard rock mines rely on the Norwegian Method of Tunnelling ground support recommendations for preliminary design recommendations. This is the case during the pre-feasibility and feasibility stages where the $Q$-system is used to select the support standards. This is usually accompanied by a limit equilibrium wedge analysis and rules of thumb. It follows that as the mine advances more geomechanical data becomes available, including rock exposures that allow for an update of the ground conditions and revision of the recommendations. As the mine develops, the ground support standards evolve further. At any given time, the implemented ground support systems for the different ground conditions are documented and updated in the mine's ground control management plan (GCMP).
\end{abstract}

This paper addresses some of the limitations of the Norwegian Method of Tunnelling as a ground support design tool for mining excavations. The results of a comprehensive review of GCMPs, successfully implemented in Australian and Canadian hard rock underground mines, are the basis of newly developed empirical guidelines calibrated to mining conditions and ground support.

\section{Introduction}

A fundamental challenge for underground hard rock mines is the engineering design of ground support systems. This is particularly difficult during the pre-feasibility and feasibility stages where there is limited access to geomechanical data. Rock mass classification systems are quite often the only approaches for estimating large-scale rock mass properties. Rock mass classification systems constitute an integral part of empirical design and can be used successfully to group areas of similar geomechanical characteristic. They can provide guidelines on excavation stability and select reinforcement and support tools. Furthermore, they provide an indication of in situ rock mass properties as input parameters for numerical models. In mining, the $Q$ classification system proposed by Barton et al. (1974) and rock mass rating (RMR) developed by Bieniawski (1976), form the basis of many empirical design methods. It should be recognised, however, that there was a limited number of mining case studies used to develop these systems. A review of the limitations of rock mass classification systems have been provided amongst other by Milne et al. (1998), Palmstrom and Broch (2006) and Hadjigeorgiou (2012).

Despite the limitations of classification systems, they are very useful, particularly at early stages of design. They are most useful in identifying geomechanical domains of similar rock mass quality. The presentation of an overall picture of a mine ground conditions can be used to define zones of elevated hazards, develop ground support strategies as a function of geomechanical models, and identify areas of further geomechanical investigations. This process is facilitated by the use of mine planning and data management software that allows efficient storage, manipulation and visualisation of geomechanical data.

Potvin et al. (2012) attribute the popularity of the RMR and Q-systems to their useful application to a number of widely used empirical design techniques relevant, for example, to caving mines (Laubscher \& Taylor 1976), open stope mines (Mathews et al. 1981; Potvin 1988), and generally to ground support design (Grimstad \& Barton 1993).

The use of classification systems to select reinforcement and support of mine drives is of particular interest. Following a benchmarking study in Canadian and Australian underground hard rock mines it was noted that 
the Grimstad and Barton (1993) chart, based on the Q-system, was the most widely used system for the preliminary selection of support. This, however, overlooks the fact that the support recommendations were drawn from civil engineering tunnels. At the same time, the RMR system (Bieniawski 1989) does not provide explicit guidelines for the selection of support.

A comprehensive review of GCMPs successfully implemented in Australian and Canadian hard rock underground mines is currently used for the development of new empirical guidelines. These guidelines will be calibrated to mining conditions and ground support systems used in the mines. The guidelines under preparation are further discussed in Section 5 of this paper.

\section{Evolution of support recommendations from the Q-system}

In discussing the development of ground support recommendations based on the Q-system, Barton et al. (1974) explained their underlying methodology.

"Different personal, national and continental engineering practices lead inevitably to variations in methods of support, even for the same quality of rock. The majority of data has been obtained from European case records due in particular to the ninety or so case records from Scandinavia (Cecil, 1970) and other Norwegian case records known to the authors. As a result of this European-Scandinavian bias, and the belief that shotcrete and bolting methods deserve most attention, many well documented case records have been ignored. These include those describing steel rib support methods, free span concrete arch roofs, and pre-cast sectional linings."

This approach by Barton et al. (1974) was justified at the time, and was in fact dictated by their objective and the available data. Although the database was mostly from tunnels in Scandinavia, in the absence of other alternatives, the Q-system has been adopted for rock characterisation and for preliminary design of support for mining context excavations. The expectations and tolerance for the design of support for mining drives are, however, quite different to civil engineering tunnels. This has significant impact on the selection of support under a different degree of conservatism. Another important consideration, in the application of the Q-system, is the evolution of rock reinforcement and surface support products since the introduction of the system in 1974. This has been somewhat addressed by a series of revisions to the support recommendations derived from tunnelling projects, and in particular the use of shotcrete. It should be noted that mine drives make extensive use of mesh as part of their ground support standards. In fact, mesh is not explicitly part of the recommended systems proposed by Barton et al. (1974), as it is rarely used in civil engineering tunnelling.

The original support recommendations based on the $Q$-system are reproduced in Figure 1 . At the time 38 support classes were proposed covering a range of rock masses from 'exceptionally good' $(Q=1,000)$ to 'exceptionally poor' $(Q=0.001)$. A simplified version of this chart was presented by Grimstad et al. (1986) and is reproduced in Figure 2. The reduction in support categories was an acknowledgement that for practical purposes, the choice of support systems could be grouped in more general categories. It is also noted that ground support practices in mining differed considerably from civil engineering and the range of ground conditions was less broad. 


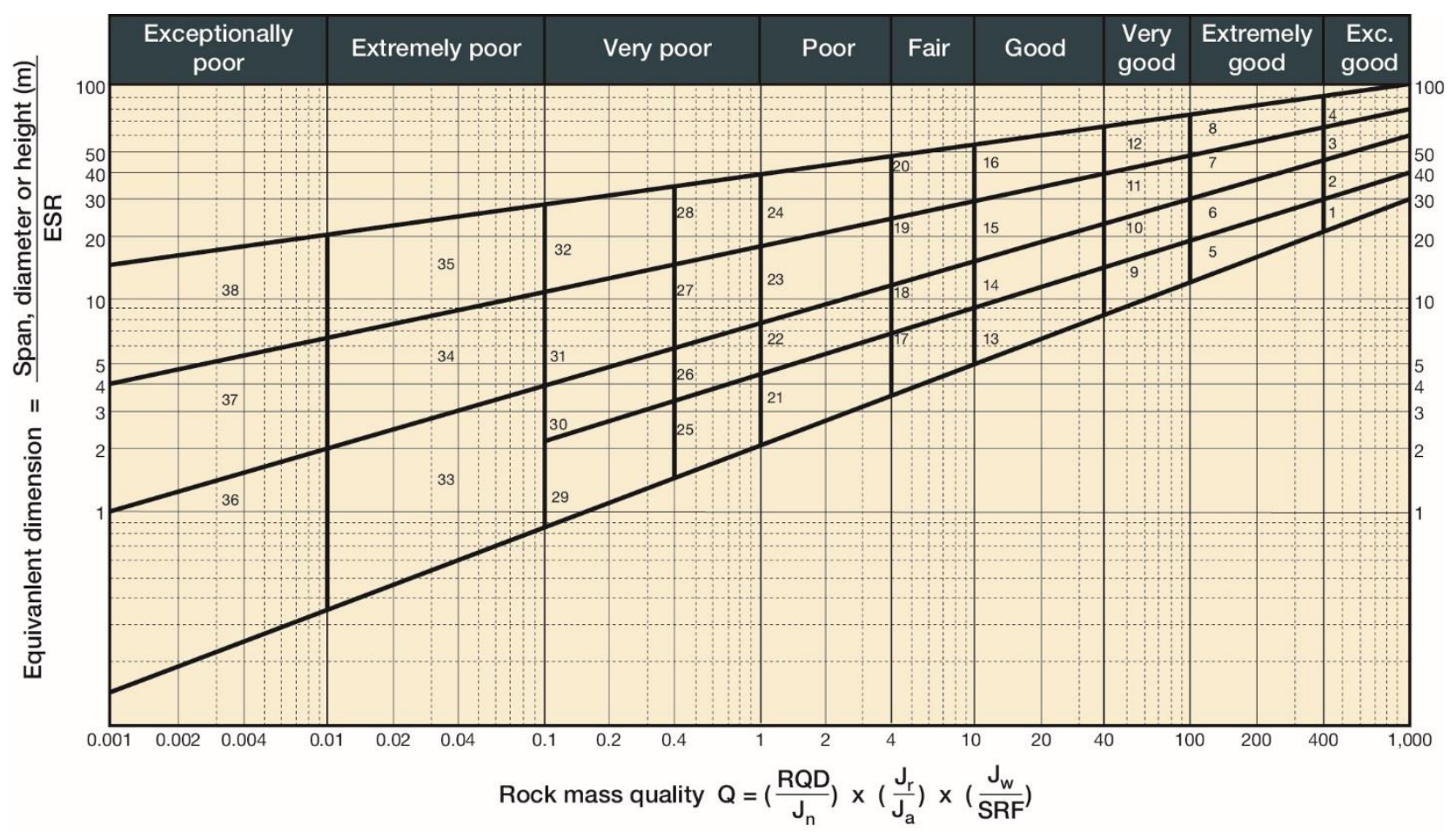

Figure 1 Support recommendations based on the Q-system, after Barton et al. (1974). The reader is to refer to the original paper for the details on the 38 categories of ground support recommended by the chart

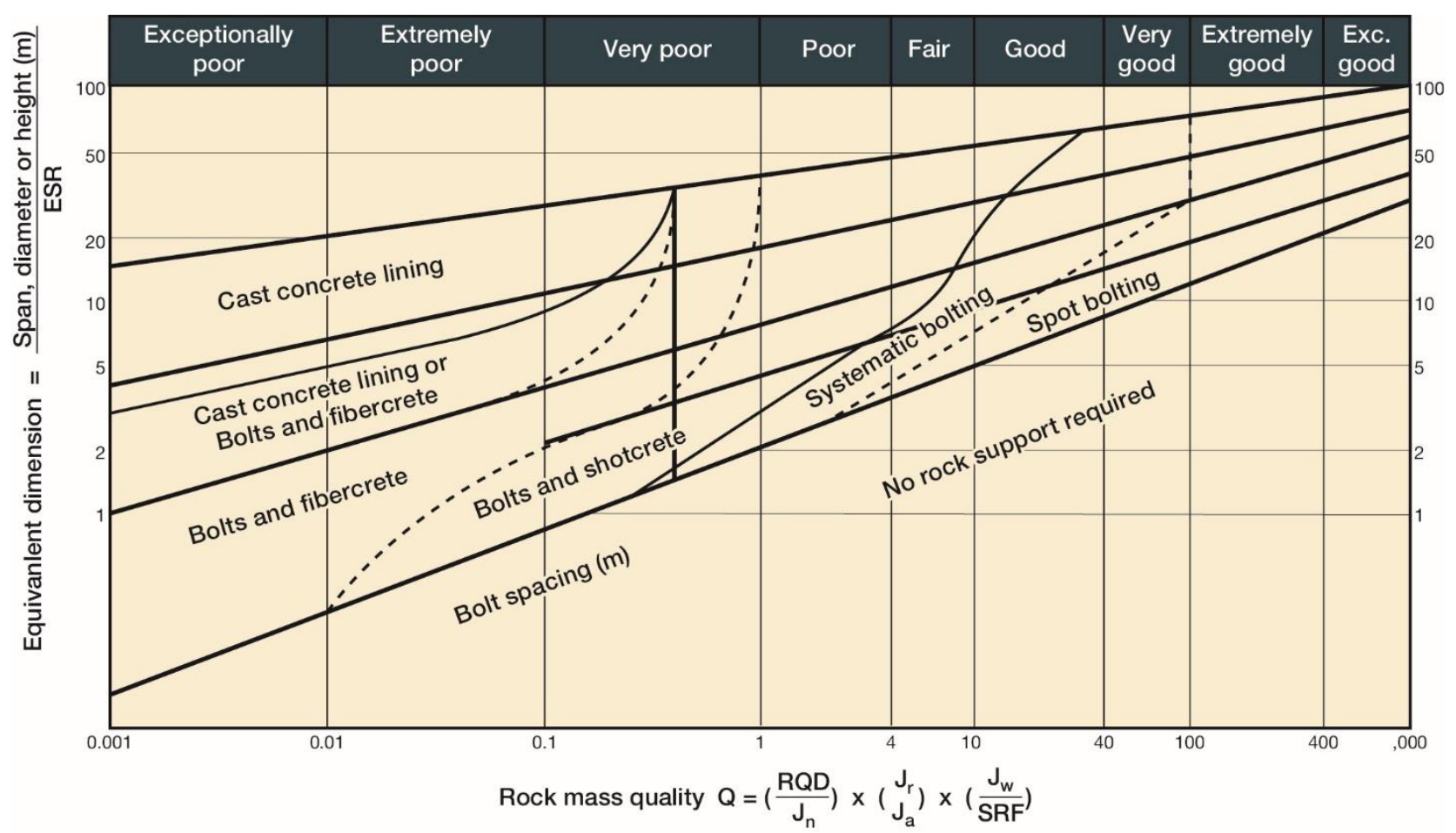

Figure 2 Simplified support recommendations based on the Q-system, after Grimstad et al. (1986), reproduced from Barton (1989)

The version of the support guidelines commonly used in mines is the one proposed by Grimstad and Barton (1993) (Figure 3). This was an important update, motivated by the need to better meet the requirements of the Norwegian Method of Tunnelling support techniques. The major change since the 1986 chart was the 
use of wet steel fibre reinforced shotcrete $S(\mathrm{fr})$, which was not available at the time of the first introduction of the Q-system in 1974.

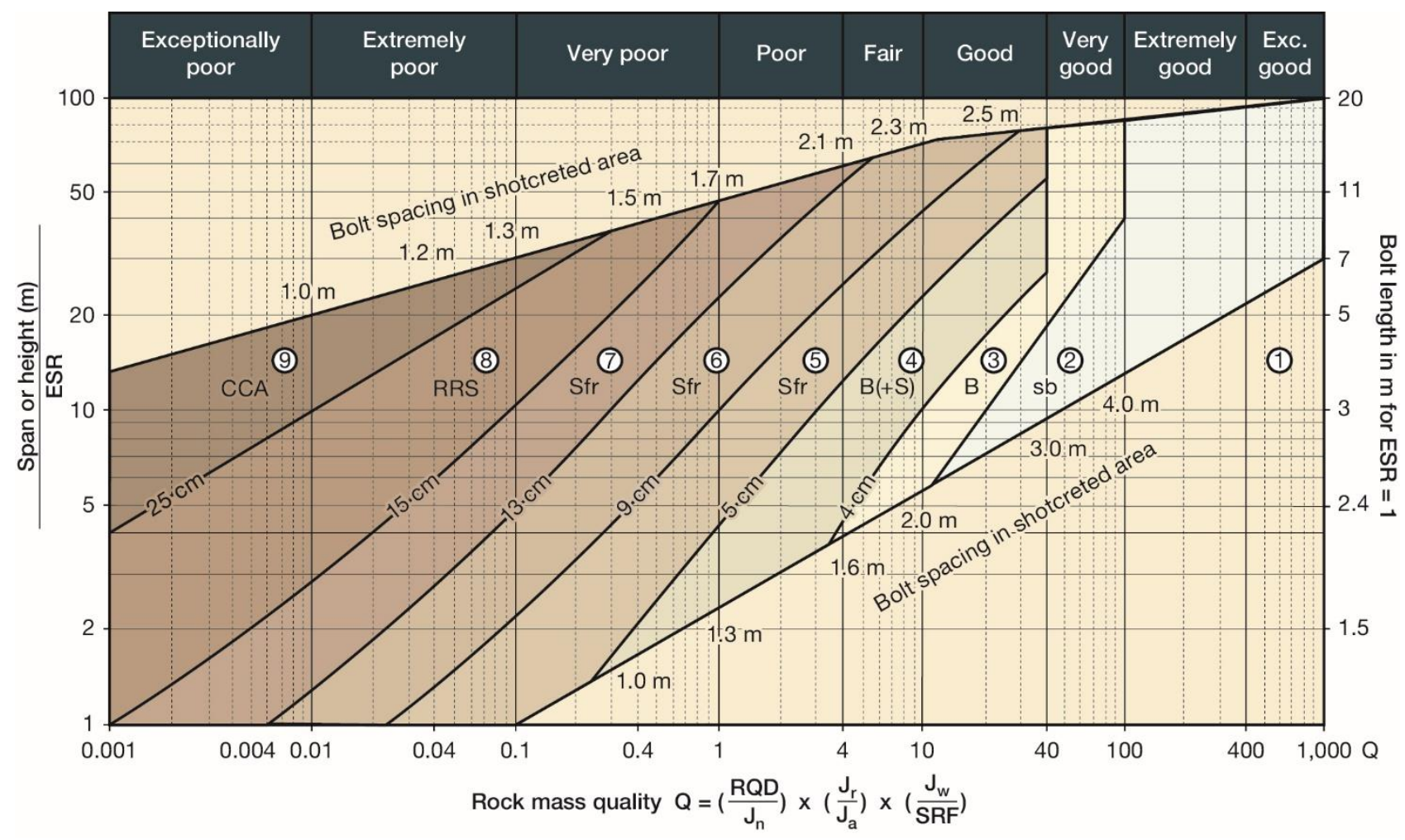

Reinforcement categories:
1) Unsupported
6) Fibre reinforced shotcrete and bolting, $9-12 \mathrm{~cm}, \mathrm{Sfr}+\mathrm{B}$
2) Spot bolting, sb
7) Fibre reinforced shotcrete and bolting, $12-15 \mathrm{~cm}, \mathrm{Sfr}+\mathrm{B}$
3) Systematic bolting, B
4) Systematic bolting (and unreinforced shotcrete, 4-10 cm), B(+S)
5) Fibre reinforced shotcrete and bolting, $5-9 \mathrm{~cm}, \mathrm{Sfr}+\mathrm{B}$
8) Fibre reinforced shotcrete. $>15 \mathrm{~cm}$, reinforced ribs of
shotcrete and bolting, Sfr, RRS+B
9) Cast concrete lining, CCA

Figure 3 Rock mass classification - permanent support recommendation based on Q and NMT. Note the extensive use of S(fr) as permanent support (after Grimstad and Barton 1993)

The 1993 version of the Q-system was also characterised by changes to the stress reduction factor (referred to in this paper as $\mathrm{SRF}_{93}$ ) ratings. The original $\mathrm{SRF}_{74}$ recommendations were found by Grimstad and Barton (1993) to be insufficient for high stress and massive rock mass.

\section{"The updating of the Q-system has shown that in most extreme cases of high stress and hard massive (unjointed) rock, the maximum SRF-value has to be increased from 20 to 400 in order to give a Q-value which correlates with the modern rock support shown in Figure 1" (reproduced as Figure 3).}

Because massive rock masses affected by high stress conditions are difficult to assess by visual observations, the approach suggests using $\sigma_{c} / \sigma_{1}$ to determine $\mathrm{SRF}_{93}$ in these conditions, which are often prone to rockbursting. According to these latest guidelines reproduced in Table 1 , a low $\sigma_{c} / \sigma_{1}$ translates into a high $\mathrm{SRF}_{93}$ value. The adequacy of the new $\mathrm{SRF}_{93}$ for deep mining is discussed in Section 4. 
Table 1 The updated $\mathrm{SRF}_{93}$ table from Grimstad and Barton (1993) with ratings compared to $\mathrm{SRF}_{74}$

\begin{tabular}{lcccc}
\hline Stress level & $\sigma_{\mathbf{c}} / \boldsymbol{\sigma}_{\mathbf{1}}$ & $\boldsymbol{\sigma}_{\boldsymbol{\theta}} / \boldsymbol{\sigma}_{\mathbf{c}}$ & $\mathbf{S R F}_{\mathbf{7 4}}$ & $\mathbf{S R F}_{\mathbf{9 3}}$ \\
\hline $\begin{array}{l}\text { Low stress, near surface, open joints } \\
\text { Medium stress, favourable stress condition }\end{array}$ & $200-10$ & $<0.01$ & 2.5 & 2.5 \\
\hline $\begin{array}{l}\text { High stress, very tight structure. Usually } \\
\text { favourable to stability, may be unfavourable } \\
\text { for wall stability }\end{array}$ & $10-5$ & $0.01-0.3$ & 1 & 1 \\
\hline $\begin{array}{l}\text { Moderate slabbing after }>1 \text { hour in massive } \\
\text { rock }\end{array}$ & $5-3$ & $0.5-0.65$ & $5-9$ & $0.5-2$ \\
$\begin{array}{l}\text { Slabbing and rockburst after a few minutes } \\
\text { in massive rock }\end{array}$ & $3-2$ & $0.65-1$ & $9-15$ & $50-200$ \\
\hline $\begin{array}{l}\text { Heavy rockburst (strain-burst) and } \\
\text { immediate dynamic deformations in } \\
\text { massive rock }\end{array}$ & $<2$ & $>1$ & $15-20$ & $200-400$ \\
\hline
\end{tabular}

\section{Limitations of current Q-system support recommendations}

The applicability of the support recommendations through the use of the Q-system for civil engineering has been questioned by Palmstrom and Broch (2006). They reproduced the bolt spacing in non-sprayed areas to indicate the data scatter to highlight the limitations of the bolt spacing of the Q-system (Figure 4). The data scatter was acknowledged in the original work of Grimstad and Barton (1993).

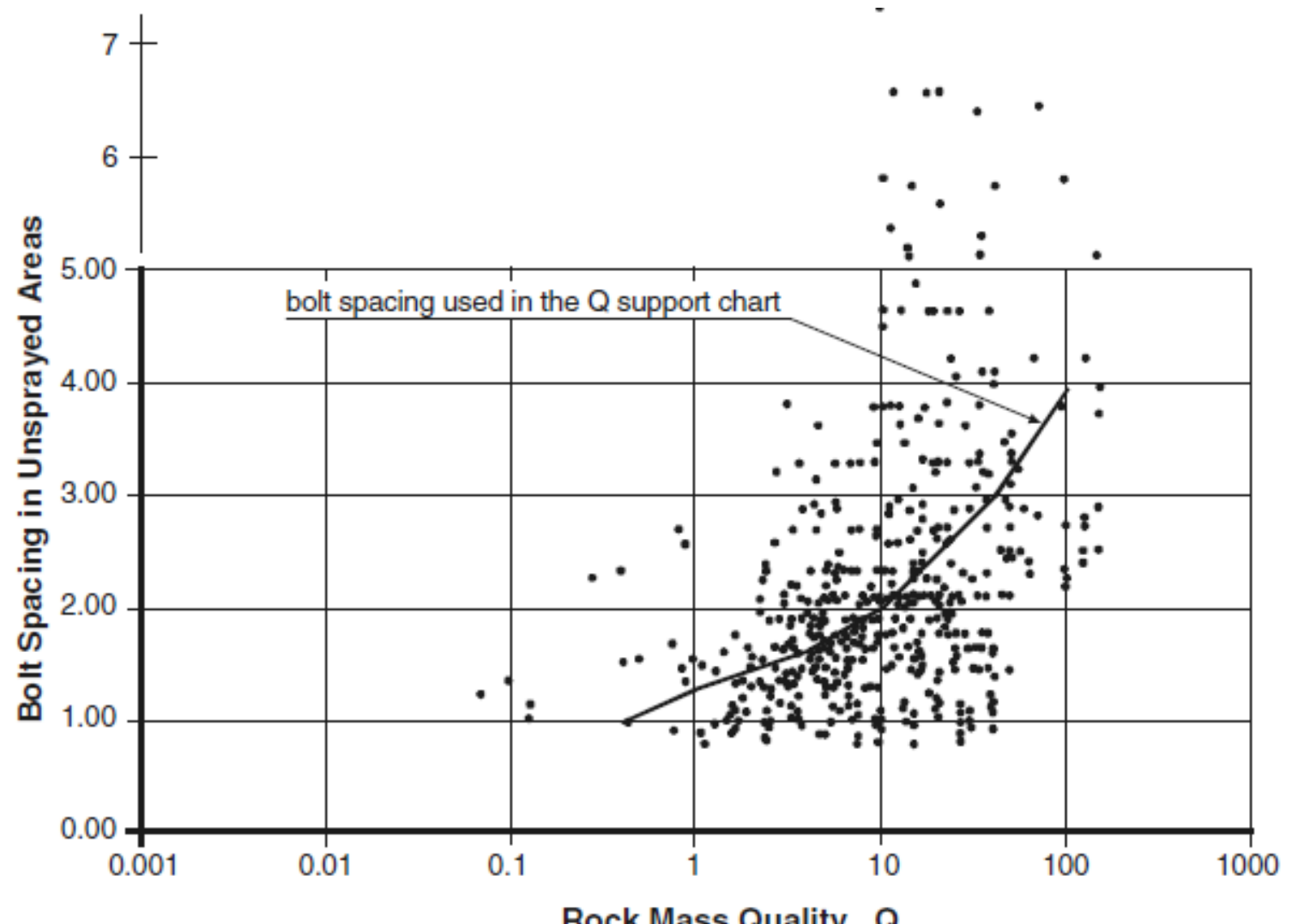

Figure 4 Bolt spacing related to Q-value in unsprayed areas (modified from Grimstad \& Barton 1993). The line indicates the bolt spacing used in the $Q$ support chart (after Palmstrom \& Broch 2006) 
Palmstrom and Broch (2006) suggest that the applicability of the Q-system is further limited in extremely and exceptionally poor ground conditions, on the basis that these conditions are difficult to characterise. The other part of the recommendations that they take issue with is that the smallest dimensions of an excavation where the predicted rock support can be executed, will be 2-3 m, and that design for large spans of 30 to $40 \mathrm{~m}$ should not be based just on a classification system. Consequently, they suggested a two stage approach in which $Q$ can be used independently for support recommendations and areas where it is imperative to use supplementary methods of analysis (Figure 5).

In effect, most of the issues raised by Palmstrom and Broch (2006) are applicable to most classification systems. Another concern is that potential users at times are oblivious to the limitations. In effect, it is sometimes overlooked and the classification systems are often used outside their range of application supported by past experience and case studies.

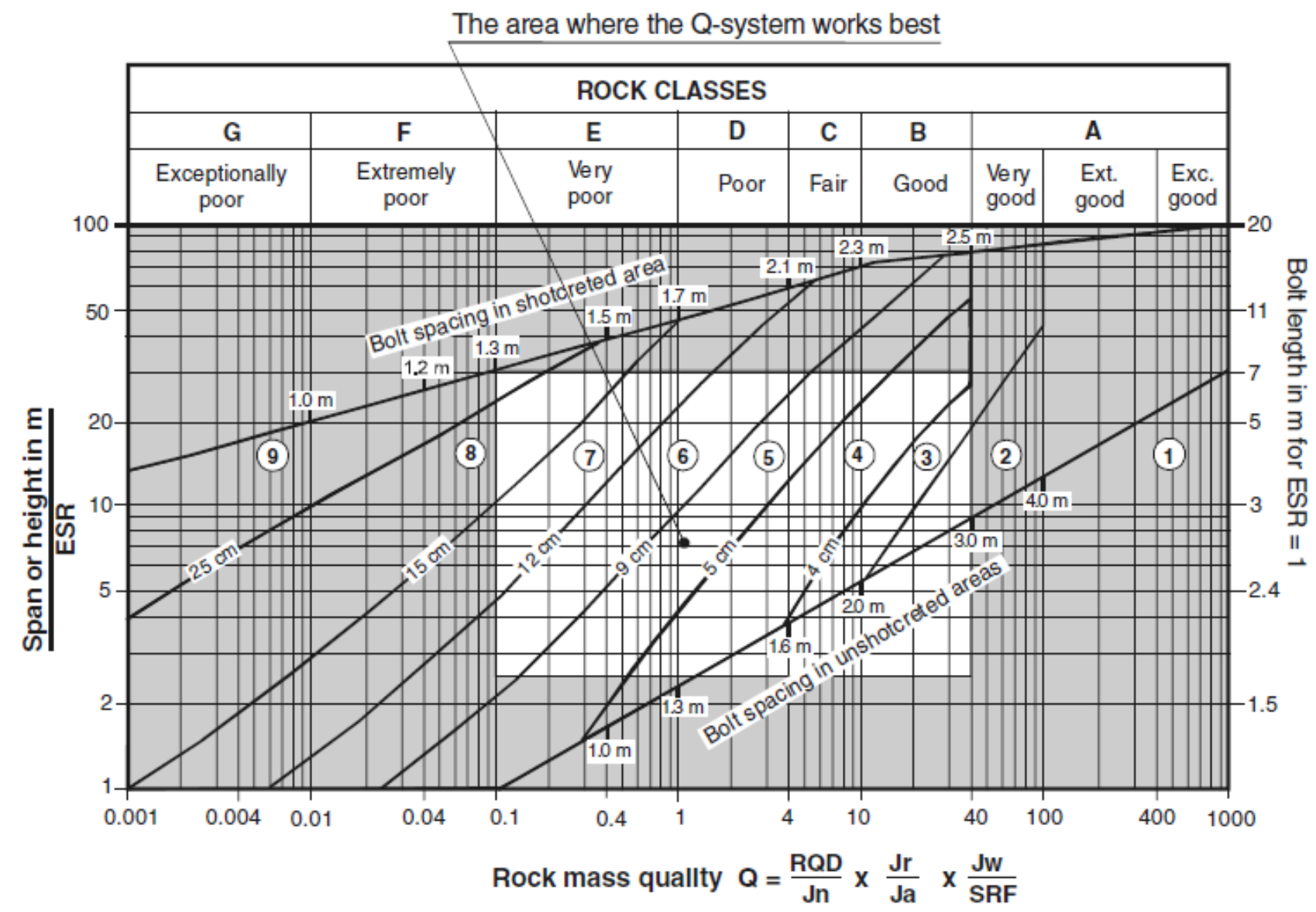

Reinforcement categories:

1) Unsupported
2) Spot bolting
3) Systematic bolting
4) Systematic bolting (and unreinforced shotcrete, $4-10 \mathrm{~cm}$ ),
5) Fibre reinforced shotcrete and bolting, $5-9 \mathrm{~cm}$

Figure 5 Applicability and limitations in the Q rock support diagram, after Palmstrom and Broch (2006)

Peck and Lee (2007) have focused on the pertinence of the support recommendations of the Q-system to underground hard rock mines in Australia. They note that the original version of the Q-system did not have mining and, in particular, cases from Australian hard rock mines in its database. The other issue raised was that in the Q-system, rockbolts imply $20 \mathrm{~mm}$ diameter solid mild steel bolts, fully grouted using either cement or resin. Their concern was that the Australian mining industry makes extensive use of lower load bearing capacity friction bolts. They report of a study that resulted in 59 datasets from 15 mine sites drawn from all six Australian states and the Northern Territory. Nearly all of the data applies to $5.5 \mathrm{~m}$ wide and 
variably arched development. For the purposes of their analyses, they made a distinction between the capacity of the employed friction anchors ( 3 tonnes), solid bar bolts ( 15 tonnes) and cable bolts ( 21 tonnes). No capacity allowance was made for mesh or fibrecrete. Figure 6 plots the assigned Q-value for each case study against the installed support capacities. It is interesting that this graph plots support from 0.01 to 100 , which is similar to the defined applicability of the Q-system independently suggested by Palmstrom and Broch (2006). Assuming that Q-values were appropriately assessed and the installed support is just adequate, Figure 6 suggests that there is a tendency in the Australian mining environment for the Q-system to underestimate the support required for the 'good' and 'very good' rock classes (probably due to the $\mathrm{OH} \& \mathrm{~S}$ considerations discussed above) and to overestimate support requirements for 'poor' to 'extremely poor' rock classes. It was also noted that only 3 out of 30 sites required rehabilitation which was interpreted that local experience demonstrated that some sites were stable with less support than predicted by the $Q$ system.

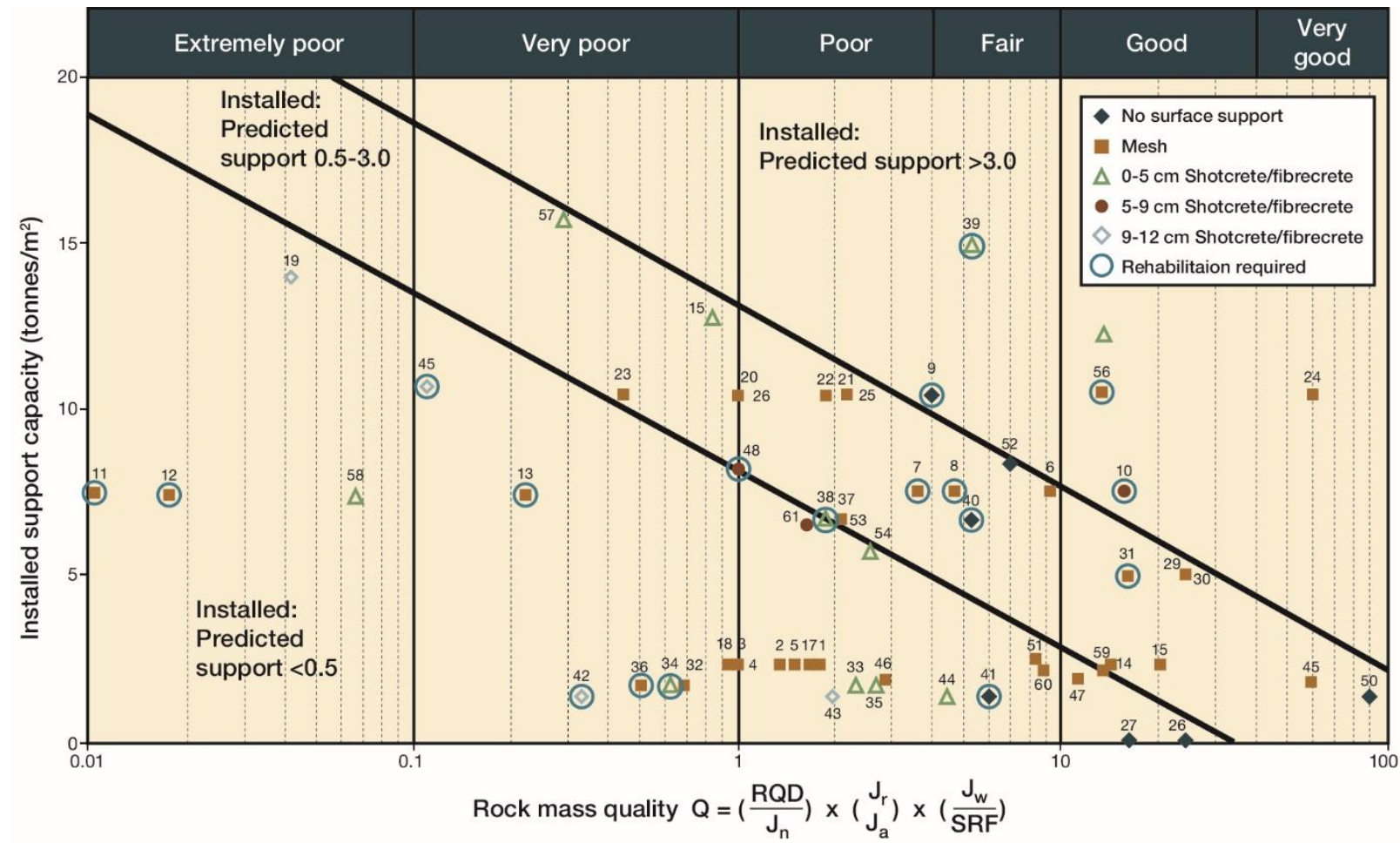

Figure 6 Installed support capacity versus Q (after Peck and Lee 2007)

Peck and Lee (2007) calculated the predicted permanent support capacity as a function of $Q$ based on empirical equations proposed by Barton et al. (1974) and in effect ignored the contribution of mesh and fibrecrete as part of the installed support. It should be recognised that a number of assumptions were made in developing the permanent support pressure by Barton et al (1974) and in the work of Peck and Lee (2007). In particular interpreting the way the performance of rockbolts was related to their capacity. This is valid in cases where the bolts reinforce individual blocks, defined by joint sets, or are required to support the dead weight. In pattern or systematic bolting, the role of rockbolts lies in reinforcing the rock mass (rather than supporting dead weight) as outlined in Stillborg (1994) and Hadjigeorgiou and Charette (2001), and as such, the bolt full capacity is not necessarily solicited.

\section{$4 \quad$ Benchmarking and further limitations of the Q-system support recommendations in mining}

The authors are currently working on a review of ground support practices in Australian and Canadian underground hard rock mines, based on more than 60 GCMPs (and a number of interviews of mining engineer practitioners). The GCMPs show that for determining preliminary support recommendations, 
approximately $75 \%$ of the mines use the Q-system, in combination with other methods such as; the limit equilibrium software Unwedge (RocScience 2011) used for preliminary design along tunnel intersections in $55 \%$ of the mines, and some form of numerical modelling at $20 \%$ of the mines.

It is worth noting that the actual support system implemented at mine sites often diverts significantly from the design recommendations from the above methods. This is not surprising given the origin of the support recommendations of the Q-system closely aligned to civil tunnelling as opposed to mining. At the same time, recommendations based on limit equilibrium or stress analysis software are perceived as conceptual as opposed to design tools for reinforcement purposes. These differences can be linked both to the support philosophy and choice of support systems.

Furthermore, the ground control standards at hard rock mines are generally the result of an evolution, starting with the feasibility recommendations (in most cases based on the Grimstad \& Barton 1993 chart) and adapting them to changes in ground conditions and what has worked best at that mine over time. The implemented ground support systems are therefore compatible with ground behaviour and installing equipment capability and dimensions with respect to excavation size.

The extensive review of GCMPs from Australia and Canada has shown that most mines have not adopted the new $\mathrm{SRF}_{93}$ guidelines proposed by Grimstad and Barton (1993) for massive and highly stressed rock mass (Table 1) and use the original $\mathrm{SRF}_{74}$ estimation, in combination with Figure 3 , to guide their selection of ground support systems. This is an interesting finding since the $\mathrm{SRF}_{93}$ changes were specifically motivated to fit this support design chart.

Perhaps the following observations can contribute to explain the difficulties in using $\mathrm{SRF}_{93}$ (Table 1) in mining applications. It is the authors experience that rockbursting conditions in deep mines are often the result of combining stiff and strong rock (often high $\sigma_{c}$ ) with high stress (high $\sigma_{1}$ ) and as such, a low $\sigma_{c} / \sigma_{1}$ is not always a good indicator of rockbursting conditions. Furthermore, the very large change proposed in the $\mathrm{SRF}_{93}$ ratings, from 20 to 400, contributes to a drastic change in the assessment of the Q-value, in high stress conditions, from previous practices. The visual appearance of a poor rock mass with, for example, a $Q$ of 2 (with a $\mathrm{SRF}_{74}$ of 20 in the old system) is the same as Q of 0.1 (with a $\mathrm{SRF}_{93}$ of 400 in the new system). Previous work from Peck (2000) and Peck and Lee (2007) tend to corroborate the above observations related to deep mining and the 1993 changes of SRF.

It was also found by Peck and Lee (2007) that the excavation support ratio (ESR) factor, which effectively modifies the span according to the application (from temporary mine openings to nuclear waste disposal caverns), appears to lead to some confusion for mining application users as to which ESR number is appropriate. Of interest is their observation "that the appropriate minimum ESR value is 1.3 for all human-access development, whether it is permanent or just a temporary stope access" (Peck \& Lee 2007).

It should be taken into consideration that the ESR reduces the effective span and "reflects construction practice in that the degree of safety and support demanded by an excavation is determined by the purpose, presence of machinery, personnel, etc." Barton (1988). For mining applications, the Q-system recommendation is for an ESR of 3 to 5 for temporary openings and 1.6 for permanent mine openings. It should be noted that in the original database used to develop the Q-system, there were only two cases of temporary mine excavations, Barton et al. (1974). Furthermore, the predominant tunnel dimensions (span or diameter) were 5 to $10 \mathrm{~m}$ (78 cases) and 10 to $15 \mathrm{~m}$ (59 cases). In providing an assessment of the database, Barton (1988) noted the large number of case records collected from hydroelectric projects, which included 40 cases of large caverns with spans in the range of 15 to $30 \mathrm{~m}$ and wall heights in the range of 30 to $60 \mathrm{~m}$. This underlies the underrepresentation in the database of typical mine drive spans of 4-6 m.

In effect, ESR acts as an indirect approach to introduce a Safety Factor in the design. In practice, mines do not apply different Safety Factors between permanent (long-term) and temporary (short-term) mine drives. This is because mine workers must access extensively these mine drives and are exposed to potential rockfalls in both cases. In effect, the bolting pattern or the surface support intensity would generally not be significantly different between short and long term support. The only differentiation most mines appear to make for short- and long-term ground support is in the selection of corrosion-resistant products. 
In summary, and based on mining experience, for mining drives at least, it is suggested that when used in connection with a Q-rating for support recommendations, the use of ESR has found limited success. The ESR is often used inconsistently with respect to the actual rating value to be used and the inherent conservatism of the given values. Even then, it is recognised that the original database does not have a good representation of mining drives. The actual support recommendations do not address the pertinence of long-term versus short-term performance of support in mines.

\section{Towards new empirical ground support design guidelines for mine drives}

The GCMPs are a valuable source of data from which new guidelines, well adapted to mining practices, could be developed. This is because GCMPs contain extensive information about ground conditions and ground support. This information is constantly updated as knowledge of the ground conditions evolves and ground support practices are optimised. In certain jurisdictions, and in certain mining companies, it is a requirement that the GCMP is reviewed on an annual basis. Therefore, it is reasonable to assume that the ground support standards documented in the GCMPs are a good reflection of successful ground support practices for the ground conditions in which they are applied. The widely used empirical approach based on the Q-system and the many limitations in applying it to mining conditions emphasises the need for improving the method. At the present time, given its broad application in Australian and Canadian mines, the Q-system still appears to be the most appropriate of the rock mass classification systems for the preliminary design of support. The challenge is to improve the database for mining purposes and using rock reinforcement and surface support systems shown to be successful at mine drives as opposed to civil engineering tunnels.

The development of new empirical ground support design guidelines for underground mine drives is a work currently in progress by the authors. It is recognised that for these guidelines to be of use and gain acceptability they must be compatible with current practice at mine sites. Therefore, similarly to Grimstad and Barton 1993 chart used at approximately 75\% of the mines that provided GCMPs for the review, the new guidelines should relate ground support practice to ground conditions and excavation span. It is reasonable to continue using the Q-system to characterise the ground conditions. It is a system that captures adequately the ground conditions at mines and is already widespread and accepted in the mining industry. The development of ground support recommendations based on the Q-system is expected to continue to evolve to reflect the rock reinforcement and surface support tools accessible and employed at mine sites.

However, the SRF issue must be addressed. A factor to account for stresses within the Q-system, which is representative of deep mines, is necessary in order to reflect the increase in ground support requirement in high stress environments. The original $\mathrm{SRF}_{74}$ was deemed inadequate for high stress according to Grimstad and Barton (1993), but the new $\mathrm{SRF}_{93}$ has not been adopted by industry. This could be due to the lack of awareness or a perception that it is inappropriate. There is evidence that in its present form it may not be representative of rockbursting conditions in deep mines. The approach proposed by Peck (2000) and Peck and Lee (2007) could eventually provide a path forward.

The use of the ESR ratio or similar factor to modifying excavation span as a way to apply a built-in Safety Factor will not be required in the mine drive support guidelines. In fact, the variability of mine drive spans in Australia and Canada generally varies only from 4 to $6 \mathrm{~m}$ in width and height. A direct relationship between span, Q-ratings and ground support requirement could be sufficient. It would appear that design of larger excavations in a mining context would arguably require further analysis.

Keeping in mind that these types of empirical ground support guidelines are best used at feasibility study, as a first pass design with the intent to optimise it later, the key design parameters to be determined at that stage include:

- Bolt density. 
- Bolt length.

- The use of shotcrete versus mesh.

- The thickness of shotcrete if selected.

- Reinforcement wall coverage: to install reinforcement to gradeline (3.5 $\mathrm{m}$ from the floor) or close to the floor (say approximately $1 \mathrm{~m}$ ).

- Surface support wall coverage: to install surface support to gradeline ( $3.5 \mathrm{~m}$ from the floor) or close to the floor.

There is a wide variety of ground support products available on the market, and the guidelines under development will not go into the details of suggesting preference for any types of product. This is because the selection of specific ground support products and techniques are not only a function of the rock mechanics requirements but often the selection is overridden by local mining culture, equipment used, product availability and cost, quality control issues, and many other factors.

This will bring some limitations to the guidelines. It is important to realise that the load bearing and deformation capacity can vary considerably between different products, as pointed out by Peck and Lee (2007). However, it is emphasised that the database of successful ground support systems from the GCMPs, which is being used to develop the new guidelines, includes the majority of ground support products. The guidelines do not rely on capacity calculations, but simply on the empirical relationship between, $Q$, span and the bolting density and length (of many mixed types of bolts) combined with surface support practices. In other words, the lowest capacity products would be accounted for in the design guidelines.

One reinforcement product differentiation that could be easily identified in the database is that long term excavations are reinforced with grouted bolts, typically $20 \mathrm{~mm}$ resin or cement grouted rebars, whilst the application of friction bolts are often restricted to short-term excavations. Galvanised products are also common in longer term excavations. Weld mesh is used in most mines because of the ease of installation.

Dynamic or yielding reinforcement are increasingly popular in deep and high stress mines and a number of new products have been made available on the market during the last decade. At this stage, there might not be enough empirical data to include dynamic support in the new guidelines. Furthermore, it is unlikely that a simple relationship between span and $Q$ would allow deriving guidelines into such a complex problem as dynamic loading, especially given the situation with SRF described earlier. Parameters related to the magnitude of the largest possible seismic events would necessarily need to be accounted for. Therefore, dynamic ground support will not be included in the guidelines under development.

\section{Conclusion}

New empirical ground support design guidelines for mine drives are under development based on GCMP, as they contain extensive and updated information on ground conditions and ground support. The need for new guidelines arises from the realisation that the Grimstad and Barton (1993) graph is extensively used in the mining industry, and that there are many limitations, either ignored or previously unidentified by the users. The popularity of this design graph is largely due to there not being any other practical alternatives for empirical evaluation of support designs at feasibility study stage.

As for the limitations of the popular Grimstad and Barton (1993) graph, firstly the database used to build the graph is entirely from civil engineering, and secondly the guidelines have been developed based on a large scatter of bolting patterns, as pointed out by Palmstrom and Broch (2006). More importantly, it is self-evident that the many differences between civil tunnelling and mining cannot be embodied into the ESR factor alone. For example, the extensive use of friction bolts and mesh in mining, which are absent in the chart, provides evidence of these differences. Peck and Lee (2007) have also expressed concerns about combining the low capacity of a friction bolt used in mining with the Grimstad and Barton (1993) graph which contained only high capacity rebars. 
The changes between $\mathrm{SRF}_{74}$ and $\mathrm{SRF}_{93}$, which were meant to better represent massive rock under high stress conditions, have been ignored by the mining industry, despite the fact that the design chart is meant to be applied with $\mathrm{SRF}_{93}$. Technically, because this is an empirical system, it is not appropriate to extrapolate from civil to mining practices and, furthermore, to use factors which are different ( $\left.\mathrm{SRF}_{74}\right)$ than the ones used for developing the chart ( $\left.\mathrm{SRF}_{93}\right)$.

The new guidelines being developed will try to address most of the above issues and provide a practical tool for mine designers to assess ground support requirements empirically. The key design parameters will include:

- Bolt density.

- Bolt length.

- The use of shotcrete (or fibrecrete) versus mesh.

- The thickness of shotcrete (or fibrecrete) if selected.

- Reinforcement wall coverage - to install reinforcement to gradeline (3.5 $\mathrm{m}$ from the floor) or close to the floor (approximately $1 \mathrm{~m}$ ).

- Surface support wall coverage - to install surface support to gradeline ( $3.5 \mathrm{~m}$ from the floor) or close to the floor.

\section{Acknowledgement}

The authors acknowledge the mining companies that provided access to the ground control data and thank the following sponsors of the Ground Support System Optimisation (GSSO) project, at the Australian Centre for Geomechanics, The University of Western Australia: Glencore Mount Isa Mines Limited; Independence Group Long Nickel Mine; Codelco Chile (NML); MMG Limited; Australian Centre for Geomechanics; Minerals Research Institute of Western Australia (MRIWA); Dywidag Systems International (DSI); Jennmar Australia; Fero Strata; Atlas Copco; Golder Associates Pty Ltd; and Geobrugg Australia.

\section{References}

Barton, N 1988, 'Rock mass classification and tunnel reinforcement selection using the Q-system', in L Kirkaldie (ed.), Rock classification systems for engineering purposes, American Society for Testing and Materials, Philadelphia, pp. 59-88.

Barton, N 1989, 'Cavern design for Hong Kong rocks', in AW Malone \& PGD Whiteside (eds), Rock cavern - Hong Kong, The Australasian Institute of Mining and Metallurgy, Melbourne, pp. 179-202.

Barton, N, Lien, R \& Lunde, J 1974, 'Engineering classification of rock masses for design of tunnel support', Rock Mechanics and Rock Engineering, vol. 6, no. 4, pp. 189-236.

Bieniawski, ZT 1976, 'Rock mass classification in rock engineering', in ZT Bieniawski (ed.), Exploration for Rock Engineering: Proceedings of the Symposium on Exploration for Rock Engineering, A.A. Balkema, Lisse, pp. 97-106.

Bieniawski, ZT 1989, Engineering rock mass classifications, John Wiley \& Sons, New York, NY.

Grimstad, E \& Barton, N 1993, 'Updating the Q-system for NMT', in C Kompen, SL Opsahl \& SL Berg (eds), Proceedings of the International Symposium on Sprayed Concrete, Norwegian Concrete Association, $21 \mathrm{p}$.

Grimstad, E, Barton, N, Lien, R, Lunde, J \& Løset, F 1986, 'Classification of rock masses with respect to tunnel stability - new experiences with the Q-system', Fjellsprengningsteknikk, Bergmekanikk, Geoteknikk, pp. 30.1-30.18. [In Norwegian]

Hadjigeorgiou, J 2012, 'Where do the data come from?', Mining Technology, vol. 121, no. 4, pp. 236-247.

Hadjigeorgiou, J \& Charette, F 2001, 'Rock bolting for underground excavations', in WA Hustrulid \& RL Bullock (eds), Underground Mining Methods: Engineering Fundamentals and International Case Studies, Society for Mining, Metallurgy \& Exploration, Littleton, CO, pp. 547-554.

Laubscher, DH \& Taylor, HW 1976, 'The importance of geomechanics classification of jointed rock masses in mining operations', in ZT Bieniawski (ed.), Proceedings of the Exploration for Rock Engineering Symposium, Balkema, Rotterdam, pp. 119-128.

Mathews, KE, Hoek, E, Wyllie, DC \& Stewart, S 1981, Prediction of stable excavation spans for mining at depths below 1,000 metres in hard rock / Golder Associates, CANMET Library \& Documentation Services Division, Vancouver.

Milne, D, Hadjigeorgiou, J \& Pakalnis, R 1998, 'Rock mass characterization for underground hard rock mines', Tunnelling and Underground Space Technology, vol. 13, no. 4 pp. 383-391.

Palmstrom, A \& Broch, E 2006, 'Use and misuse of rock mass classification systems with particular reference to the Q-system', Tunnelling and Underground Space Technology, vol. 21, pp. 575-593. 
Peck, WA 2000, 'Determining the stress reduction factor in highly stressed jointed rock', Australian Geomechanics, vol. 35, no. 2, pp. 57-60.

Peck, WA \& Lee, MF 2007, 'Application of the Q-system to Australian underground metal mines', in C Mark, R Pakalnis \& RJ Tuchman (eds), Proceedings of the International Workshop on Rock Mass Classification in Underground Mining, National Institute for Occupational Safety and Health, Cincinnati, OH, pp. 129-140.

Potvin, Y 1988, 'Empirical open stope design in Canada', PhD thesis, University of British Columbia.

Potvin, Y, Dight, PM \& Wesseloo, J 2012, 'Some pitfalls and misuses of rock mass classification systems for mine design', Journal of the Southern African Institute of Mining and Metallurgy, vol. 112, pp. 697-702.

Rocscience 2011, Unwedge 3.0 software, https://www.rocscience.com/rocscience/products/unwedge

Stillborg, B 1994, Professional Users Handbook for Rock Bolting, 2nd edn, Trans Tech Publications Ltd, Zürich. 